\title{
Ensino de História como reativação do político ${ }^{1,2}$
}

History Teaching as Reactivation of the Political

Renata da Conceição Aquino da Silva*

\section{RESUMO}

Este artigo busca sugerir uma resposta à seguinte pergunta: o que torna o ensino de História significativo? Argumento que ele se torna significativo quando consegue fazer estudantes vislumbrarem um futuro disponível sobre o qual agir. Para tal, pensa-se a aprendizagem como resposta a lacunas criadas nos estudantes enquanto auditório da operação historiográfica escolar stricto sensu. Dado que uma série de transformações desatualizaram os tropos do progresso e de um futuro aberto, vive-se uma crise de representação do tempo que demanda um olhar atento para práticas escolares que têm sucesso apesar desta conjuntura. Assim, defende-se que um dos momentos onde este ensino se torna significativo é quando ele instaura um público e seu caráter político é reativado, uma das formas possíveis de temporalizar os estudantes num tempo com um futuro disponível.

Palavras-chave: disponibilidade da História; esfera pública; reativação do político.

\section{ABSTRACT}

This article aims to suggest an answer to the following question: what makes the teaching of History meaningful? I propose to answer it by arguing that it becomes meaningful as it makes students feel agents of history by opening up futures that can be acted upon. For such, learning is thought to be an answer to gaps opened up in the students when they are the public of the stricto sensu historiographic school operation. Given that many changes outdated the progress and open future's tropes, we live under a time representation crisis that demands a close look to school practices that succeed despite this crisis. Thus it is argued that one of the moments when this teaching becomes meaningful is when it creates a public and its political character is reactivated, one of the possible ways of temporalizing students in a time with an available future.

Keywords: availability of History, public sphere, reactivation of the political.

Uma justificativa importante ao argumentar a importância do ensino de História para todas e todos no ensino básico é o seu potencial de promotor da conscientização de estudantes sobre a historicidade de suas posições na socieda-

\footnotetext{
* Universidade Federal Fluminense (UFF), Niterói, RJ, Brasil. renatacas@id.uff.br
} 
de. Defende-se que a aprendizagem da História pode e deve desenvolver sensibilidade para com a condição temporal dos acontecimentos e das organizações humanas. Essa sensibilidade, articulada ao conhecimento ou reconhecimento de conjunturas diversas que perpassam as vidas de alunas e alunos, criaria a possibilidade de conexões e críticas ao passado que mudam a interpretação do presente e criam expectativas para o futuro, construindo uma cultura democrática ampla de vivência rica com as diferenças.

Esse traço do conhecimento histórico de interdependência entre passado, presente e futuro, já que mudanças em cada um deles levam a mudanças - de interpretações, expectativas e planejamentos - também nos outros (KOSELLECK, 2006), caracteriza as aulas de História como potenciais criadoras de situações e espaços específicos. A aula de História, enquanto um dos lugares de difusão e produção do conhecimento histórico, possui esse traço "ao quadrado": traz consigo esta consciência da temporalidade do seu conhecimento de referência, e tem essa característica duplicada por seu objetivo explícito de formar alunas e alunos que trazem consigo para a escola uma série de visões sobre o passado e projetos ao futuro.

Em nosso presente, os conceitos e categorias que servem de "pontos nodais" para a experiência do tempo possuem uma articulação temporal distinta. De fato, a aceleração social gera uma experiência de dessincronização que torna mais adequado falar em nossos presentes, no plural. Diferente dos tempos nos quais ocorreu a disciplinarização da História, caracterizados na historiografia feita pela elite por uma sensação de futuro nacional aberto e a ser construído, são hegemônicas agora categorias neoliberais como flexibilidade, que pregam a adaptação a sucessivos presentes (TURIN, 2019, p. 19) e um escalonamento grave da crise ambiental. Presenciamos o surgimento e difusão de conceitos como "desespero climático", ${ }^{3}$ que nomeiam a angústia de jovens com um futuro que parece cientificamente marcado como o fim do mundo que conhecemos. Vide o crescimento do uso do termo antropoceno (CRUTZEN e STOERMER, 2000) e a invenção de similares como capitaloceno (MOORE, 2017) e plantationceno (HARAWAY, 2015). Como ensina a história dos conceitos, a ampla aceitação e difusão destes neologismos os evidencia como significantes razoáveis da nossa experiência temporal. É nesta tematização das condições das experiências temporais que essa pesquisa se inscreve.

Este artigo busca sugerir uma resposta à seguinte pergunta: o que torna o 
ensino de História significativo? Para apresentar ao campo uma resposta, será primeiro definido o que se está chamando de aprendizagem significativa em História. Na seção inicial, serão articuladas as noções de aprendizagem como resposta (BIESTA, 2017) e de operação historiográfica escolar (PENNA, 2013), esta por sua vez completada com o entendimento de Ernesto Laclau sobre persuasão (2011). Na segunda seção, irei apresentar as questões em torno de definir o que é "esfera pública", para me aproximar e afastar de Hannah Arendt (2015) e articular com a definição de Laclau e Mouffe (2015), donde vai se defender que o público no ensino de História serve como uma chave de temporalização. Nesta seção, uma análise de uma aula da professora cujas aulas discuti na dissertação mostra os conceitos em funcionamento. Por fim, a terceira seção junta os fios das anteriores explicando porque simplesmente estabelecer um público em aula não é o bastante para tornar o ensino de História significativo. É necessário abraçar o político. Nas palavras finais, sugere-se ao campo uma série de perguntas para respondermos e enfrentarmos nos futuros próximos.

\section{APRENDIZAGEM SIGNIFICATIVA EM HISTÓRIA}

A pesquisa que desenvolvi no mestrado começou no grupo de pesquisa Negociando a distância entre passado, presente e futuro em sala de aula: a relação entre o tempo histórico e a aprendizagem significativa no ensino de história, criado em 2014 e coordenado pelo professor Fernando Penna (UFF). Naquele grupo, investigamos a hipótese de que uma possível aprendizagem significativa em História acontece por meio de um ensino que articule as dimensões temporais de maneira que alunas e alunos, ao entender a contingência presente em todo evento histórico e em sua consequente análise histórica, se percebessem também frente a uma história disponível para ser feita. O grupo seguiu a metodologia utilizada na pesquisa "A história ensinada: saber escolar e saberes docentes em narrativas da história escolar" de Ana Maria Monteiro, realizada entre 2005 e 2010. Nesta pesquisa, diferente de sua clássica tese de doutorado (publicada em 2007), onde os sujeitos de pesquisa foram selecionados de acordo com indicações de professores, o que guiou a seleção foi a categoria de "professor marcante" conforme apontado por alunos e alunas iniciantes no curso superior em História. No grupo Negociando a distância..., 
seguimos essa mesma metodologia (PENNA, 2014, p. 5), exceto que os questionários de pesquisa para buscar professores/as enquadrados como marcantes por seus ex-alunos foram aplicados a licenciandos que já realizavam seus estágios obrigatórios, a autora deste texto inclusa. ${ }^{4}$ Contávamos que "como futuros profissionais no estágio final de sua formação inicial, [os estagiários] já possuem um olhar diferenciado da prática docente em comparação com quando eram alunos da educação básica" (idem), donde nos focamos em estudantes do curso de História da UFF inscritos nas matérias de Pesquisa e Prática de Ensino. Perguntamos se esses alunos/as acompanhavam em seus estágios algum/a docente que tinha sucesso em tornar seu ensino significativo para os alunos e alunas, além de perguntar também como a pessoa havia chegado a esse/a professor, se já havia sido seu aluno/a e por que teria voltado. Chegamos, assim, a três professores a quem i) entrevistamos para conhecer suas histórias de vida; ii) gravamos e acompanhamos as suas aulas; iii) para dois dos professores, aplicamos questionários a suas alunas e alunos com provocações sobre questões temporais (CALDAS, 2014a, 2014b; PENNA, 2015); iv) entrevistamos novamente após o fim do acompanhamento de aulas perguntando sobre suas práticas, que haviam sido observadas por nós. Dentre estes, estava uma professora do Ensino Médio da rede estadual do Rio de Janeiro, com longa carreira na rede pública, a quem a autora deste texto acompanhou. Foram as aulas desta professora que originaram minha dissertação (SILVA, 2019), na qual investiguei por que suas aulas geraram experiências de aprendizagem significativas e marcantes inclusive ao ponto de levar várias alunas e ex-alunos a cursarem História na universidade. O presente texto atualiza algumas conclusões daquele trabalho. ${ }^{5}$

Acompanha-se aqui o entendimento de Penna (2013) sobre o ensino de História enquanto uma operação historiográfica escolar. O conceito de operação historiográfica aparece inicialmente no trabalho de Penna para abordar como se estabelece a legitimidade do conhecimento histórico ensinado. Como definiu Certeau (2002), operação historiográfica refere-se à combinação de um lugar, uma prática e uma escrita. E tanto Certeau como Ricoeur (2010), que tem uma conceituação da prática historiográfica similar à de Certeau em alguns pontos, analisam o trabalho historiador usando a publicação do texto como resultado final - um produto que é consumido somente entre seus pares. É aqui que Penna incorpora a questão incontornável a nós historiadores atualmente: ${ }^{6}$ qual é a 
função social desse conhecimento? (2013, p. 88). É esse engajamento em explicar o estudo da História sobre bases outras, quais sejam, como ela pode e deve intervir no mundo do qual faz parte - virada que Rangel e Araujo (2015) nomeiam como um giro ético-político ${ }^{7}$ - sem perder a pertinência epistemológica deste conhecimento (PENNA, 2013, p. 153-163), que leva o autor a adotar, em todos os campos de conhecimento que articula ao seu estudo, linhas interpretativas organizadas em torno de práticas articulatórias e acordos entre enunciante e leitor. Penna argumenta pela existência de duas operações historiográficas escolares distinguidas pelo auditório ao qual se dirigem: ora um auditório heterogêneo que terá acesso a textos escritos produzidos pela noosfera (a transposição didática externa), ora o auditório mais específico possível, os alunos e as alunas de uma sala de aula (a transposição didática interna) (2013, p. 165). Penna utiliza do referencial de Chevallard (1997) para discutir como os saberes circulam pela sociedade de diversas formas e, especificamente, como o saber histórico escolar não perde a sua legitimidade científica por não obedecer aos mesmos parâmetros que o saber acadêmico.

Ao utilizar os trabalhos de teóricos da retórica como ferramentas para analisar as aulas de História de um professor do Ensino Fundamental, Penna (2013) cria uma potente porta de entrada para articular as questões colocadas no início deste texto. Isto porque a retórica também compõe parte do referencial de Ernesto Laclau (1935-2014), especialmente ao final de sua obra: "uma retórica generalizada [...] transcende fronteiras regionais e se torna contínua à estruturação da própria vida social" (2014, s. p., tradução minha). ${ }^{8}$ Para trabalhar as hipóteses desta pesquisa, a aprendizagem é entendida através de uma categoria da retórica, a persuasão. Penna a utiliza para analisar a prática do professor da educação básica, o enunciante, cujo trabalho persuasivo é fazer o/a interlocutor/a compreender o que se diz (2013, p. 185) por meio de uma argumentação racional que se dá em negociação de distâncias entre os agentes (professor/a e alunos/as) e entre a história ensinada e os estudantes (2013, p. 212).

Para Ernesto Laclau, persuasão é uma operação que busca convencer alguém de algo que, a não ser que o argumento em questão seja de fundamentação algorítmica, sempre possui um certo elemento de força (LACLAU, 2011, p. 172, 175). Se aquilo em nome de que se argumenta não tem natureza algorítmica, o convencimento do/a interlocutor será resultado de alguma forma de força: assimetria de informações, uso de autoridade, alguma forma de violên- 
cia, enfim. Geralmente, persuade-se alguém através de algo menos que uma demonstração completamente racional; no que consistirá esse "algo menos", cada situação dirá (LACLAU, 1998, p. 133). Laclau também destaca que o processo de persuadir não consiste em o/a interlocutor/a ir de uma convicção $A$ para uma convicção $B$; na verdade, ele consiste em inserir uma lacuna na visão de mundo deste/a outro/a e, aí, fornecer uma chave para aquele vazio criado. Essa lacuna pode ser instaurada a partir de uma situação já conhecida, que é redescrita em termos outros, gerando esse vazio; é por isto que Laclau diz que a única forma de convencer alguém é de fazê-lo "passar da falta de convicção à convicção" (LACLAU, 2011, p. 145).

Agora, como isso nos ajuda a pensar o ensino-aprendizagem? Gert Biesta convenientemente nos lembra do papel inerentemente forçoso, violento até, da educação. Ao invés de considerar a aprendizagem como aquisição de conteúdos, vocabulário este que reforça a concepção liberal de sujeito acabado e definido pela propriedade que possui em si mesmo, por sobre a qual lhe cabe capitalizar e que abre espaço para a ideologia do "capital humano" (BROWN, 2018), ele considera a aprendizagem como "uma resposta... uma reação a um distúrbio, como uma tentativa de reorganização e reintegração em resposta a uma desintegração" (BIESTA, 2014, p. 47). A concepção de sujeito que a aprendizagem como resposta traz consigo enfatiza não só que professores/as estão sempre lidando com seres humanos em formação - ela enfatiza que o humano, durante toda sua vida, está em processo de vir ao mundo e tornar-se parte dele; não há ser humano acabado, como não há consciência humana absoluta (LACLAU, 2011, p. 48; GABRIEL, 2018, p. 240). Trabalha-se aqui com uma concepção antiessencialista do sujeito, cujo investimento teórico basilar é na historicidade e no caráter relacional de toda identidade, articulada por meio da relação com o saber desenvolvida por alunas e alunos (GABRIEL, 2018).

Pensar o sujeito como uma abertura que se reatualiza, como várias brechas que se fecham contingentemente até serem abertas novamente por outras perguntas ao longo da vida, é mais condizente com o projeto de uma educação democrática para um futuro humano (BIESTA, 2017) e com as críticas ao humano essencializado e patriarcal do contratualismo (PATEMAN, 1993). É por isto que o termo aprendizagem, em contexto neoliberal, tem tido consequências destrutivas para a educação (BIESTA, 2012, 2013, 2017; CÁSSIO, 2019): porque ele enseja pensar este processo como aquisição individual de 
posses. Para responder a isto, Biesta sugere desnaturalizar o conceito de aprendizagem para que ele seja repolitizado: o autor defende aprendizagem como um conceito avaliativo, e não descritivo (2013), ${ }^{9}$ já que considerar algo aprendizagem é um julgamento positivo de um processo pelo qual alguém passou por meio de interação com alguma coisa ou ambiente. ${ }^{10}$ Assim, entende-se aqui aprendizagem como uma resposta a uma pergunta, uma lacuna, um vazio aberto na aluna e no aluno através de ações didáticas do/a professor/a, que abre esses espaços por meio de uma negociação de distâncias entre os vários pontos de partida que aparecem nos diálogos em sala de aula (PENNA, 2013).

Por sua vez, a aprendizagem significativa em História aqui considerada que certamente é uma entre várias outras - é aquela, como já foi explicitada no início desta seção, na qual os sujeitos articulados nesta relação com o saber histórico conseguem perceber as dimensões contingentes dos eventos do passado e derivar daí a contingência dos futuros ora prognosticados pela sociedade violenta da qual fazem parte. Essa abertura de futuros foi vista nos três professores que o grupo Negociando as distâncias... acompanhou, embora tal abertura não fosse feita sempre da mesma maneira (CALDAS, 2014a, 2014b; RAMOA, 2016; PENNA, 2015). Um modo de fazer essa abertura ao futuro é instaurar em sala de aula uma esfera pública (SILVA, 2019). Uma aprendizagem significativa em História seria aquela contra uma história predeterminada, que não poderia ter sido de outra forma, ou já finalizada, aceitando um futuro apocalíptico. No entanto, é importante frisar a distância entre essa concepção de agência histórica e aquela corretamente sinalizada por Seffner (2018):

Um objetivo que comumente aparece associado ao ensino de História é o de transformar os alunos em agentes da História. Isto deve ser olhado com cautela, evitando cair numa simplificação que leve todos a serem considerados igualmente agentes da História, escondendo ou minimizando as gigantescas diferenças de poder e de possibilidade de intervenção no curso dos acontecimentos entre indivíduos situados econômica, política e socialmente em esferas distintas. (p. 39)

Defender uma aprendizagem chamada significativa em História como o sentimento por parte dos alunos de que eles são agentes históricos não é sinônimo de negar as desigualdades e assimetrias de poder que tornam alguns grupos ou indivíduos “mais agentes” do que outros, isto é, negar que no mundo presente as condições para "fazer história" são desiguais e sobredetermina- 
das por várias opressões. Ainda mais no momento em que o futuro do planeta está em jogo e isso se torna um problema para historiadores/as (CHAKRABARTY, 2013) e professores de História (GUMBRECHT, 2011). Sabe-se que as consequências da crise climática não atingirão todos os povos do mundo igualmente, apesar de sermos todos humanos e teoricamente iguais (DAVIS, 2008). Trata-se de incorporar o que alguns intelectuais têm chamado de políticas do tempo (TURIN, 2018), para politizar as temporalidades e temporalizar a política nos debates no ensino de História.

A preferência de Biesta (2017) pela noção de aprendizagem como resposta que "consiste em mostrar quem você [o/a aluno/a] realmente é" (2017, p. 47) vem da sua leitura de Hannah Arendt e da articulação que a autora faz entre existência, mundo e política. Para ela, o sujeito só pode existir e usar o potencial humano que traz consigo no nascimento se houver um mundo onde isso se realiza. Isto é, segundo ela, existir é existir politicamente e a condição disto é a existência do mundo; mundo este que não nasce conosco, mas nos precede e continuará aqui após nossa saída (2015), o que implica um trabalho de inserção das novas gerações nele e do convencimento destas da importância da preservação do mesmo para que haja um futuro para as gerações próximas existirem.

A escola como espaço de contato e entrada com este mundo arendtiano é uma chave de leitura potente. Se levarmos em conta que a existência deste mundo depende de um trabalho contínuo para sua manutenção e que é o funcionamento dele que dá as condições para que seres humanos realizem seu potencial de serem novos inícios, a escola é condição da existência da política enquanto libertação do humano. Daí o impacto dessa articulação de significantes (existência-liberdade-política-mundo) no ensino de História, já que muito da importância do ensino de História escolar é apontada justamente pelas consequências positivas e democráticas de sensibilizar os e as estudantes para os processos temporais. Acontece que no texto arendtiano há um conceito desenvolvido em profundidade que interliga suas ideias brevemente expostas aqui e que não usamos tanto: esfera pública. Passo agora a incorporar o conceito, imprescindível para pensar um ensino de História significativo conforme se está analisando aqui. 
ESFERA PÚBLICA A PARTIR DA RELAÇÃO COM O SABER

Em texto de 2016, Penna e eu nos apropriamos do conceito de público conforme Arendt o definiu em A condição humana (2015 [1958]). Desde então, a noção de público mostrou-se um ponto nodal para articular vários elementos do ensino escolar de História, na medida em que professores de História crescentemente viram suas práticas pedagógicas referenciadas no saber acadêmico serem consideradas invasões dos direitos de pais de estudantes (MOURA, 2016; SEFFNER, 2017; SILVA, 2018; SALLES, 2019).

A noção de público tem, porém, uma pluralidade de sentidos proporcional à sua importância. Uma primeira distinção pode ser feita para localizar o terreno. Frequentemente, público é sinônimo de estatal, ou então de algo que alcança muita gente, que é muito visto ou consumido. O sentido de público que esta pesquisa busca afasta-se dessas noções. Tendo Arendt como inspiração, aqui público é como uma dimensão da existência junto com outros seres humanos; ele é uma dinâmica entre os e as agentes presentes na sala de aula, que surge por meio da relação destes com os saberes ensinados/aprendidos. Ou seja: algo que surge a partir de uma relação com o saber (GABRIEL, 2018), na negociação de distâncias pela qual a operação historiográfica escolar stricto sensu é feita pelo/a professor/a. Essa dinâmica, por sua vez, não é só intersubjetiva, mas também subjetiva, por assim dizer, na medida em que a relação com o saber também pode fazer o sujeito elaborar-se enquanto sujeito e encontrar-se com seu desejo; a aprendizagem enquanto experiência é também um momento de descobrir o que se quer, dado que nenhum sujeito é transparente para si mesmo e tem completa clareza do que busca (BIESTA, 2017, p. 42).

A necessidade de articular público, política e o político para pensar o ensino de História foi a resposta encontrada para as perguntas surgidas da empiria específica que ajudei a produzir e analisei no grupo Negociando as distâncias.... Não obstante as conclusões sintetizadas e atualizadas a seguir tenham surgido de um estudo de caso, e portanto mais pesquisas empíricas sejam necessárias para que o campo verifique ao longo do tempo a amplitude da aplicabilidade das mesmas, essa pode ser uma chave de leitura potente para compreender o lugar da aprendizagem histórica na educação básica em uma disputa maior pela reabertura de futuros. Isto é, uma disputa pelas condições 
de possibilidade para uma temporalização em bases outras que não as neoliberais (TURIN, 2019, p. 49).

Inicialmente (PENNA e SILVA, 2016) argumentamos que tratar de temas do presente que corriam em jornais era também papel de qualquer professor por ser uma forma de presentificar a continuidade, ou seja, de inserir estudantes num mundo prévio à sua chegada e que continuaria existindo após sua despedida. Usávamos o referencial arendtiano, através de seus conceitos de mundanidade e de público, onde um é condição de possibilidade do outro:

Só a existência de um domínio público e a subsequente transformação do mundo em uma comunidade de coisas que reúne os homens e estabelece uma relação entre eles dependem inteiramente da permanência. Se o mundo deve conter um espaço público, não pode ser construído apenas para uma geração e planejado somente para os que estão vivos, mas tem de transcender a duração da vida de homens mortais. Sem essa transcendência em uma potencial imortalidade terrena, nenhuma política, no sentido restrito do termo, nenhum mundo em comum nem domínio público são possíveis [...] o mundo comum é aquilo que adentramos ao nascer e que deixamos para trás quando morremos. Transcende a duração de nossa vida tanto no passado quanto no futuro, preexiste à nossa chegada e sobreviverá à nossa breve permanência nele. É isso o que temos em comum não só com aqueles que vivem conosco, mas também com aqueles que estiveram antes e com aqueles que virão depois de nós. Mas esse mundo comum só pode sobreviver ao ir e vir das gerações na medida em que aparece em público. (ARENDT, 2013, p. 67)

Na passagem acima aparecem algumas características chave do público arendtiano: público como espaço-tempo de articulação de passado, presente e futuro pelo fio da permanência; único espaço-tempo no qual os seres humanos se singularizam, porque para a autora isso só pode acontecer entre outros sujeitos e fora do espaço privado (2015, p. 228, 233-235). Ela também argumenta que o ato de liberdade por excelência é o da política porque é por meio da política que os homens deixam sua marca nos tempos. Assim, discutir com estudantes as notícias de jornais para que estes percebam se e como aquilo os afeta é uma forma deles se perceberem parte do mundo e, daí, desenvolverem condições de desvelarem sua unicidade - sabendo que ela é possível por causa do mundo, tanto no futuro como no passado. O público aqui é uma chave de 
temporalização: é uma maneira de estar juntos, sincronizados, que possibilita o pensar junto.

O público arendtiano, porém, tem problemas que no decorrer da pesquisa exigiram outros referenciais: ele funciona por contraposição às esferas privada e social, cujas caracterizações são exageradamente categóricas, além de localizadas histórica e geograficamente. Para Arendt, as fronteiras entre essas esferas devem ser fixas, fazendo com que a mesma critique algumas questões, como trabalho ou manutenção da vida, sejam politizadas no debate público, uma compreensão de política e liberdade longe da história das lutas sociais. ${ }^{11}$ Essas fronteiras marcadas e o elitismo da autora em não acolher em sua reflexão as demandas por igualdade tornam seu referencial insuficiente para uma investigação fina de como a operação historiográfica escolar stricto sensu relaciona-se com demandas de igualdade, dado que, no pensamento arendtiano, igualdade só deve existir num espaço previamente definido.

Era necessário, portanto, um referencial que teorizasse a produção dos espaços públicos de maneira mais dinâmica do que a arendtiana. Foi por aqui que a teoria política do discurso (TPD) de Chantal Mouffe e Ernesto Laclau (LACLAU e MOUFFE, 2015 [1985]; LACLAU, 1990, 1999, 2011, 2013, 2014) tornou-se fundamental a esta pesquisa. A partir de agora ela nos ajuda a não somente compreender a criação de uma esfera pública, mas também a relação entre política/político e futuros disponíveis. A TPD é desenvolvida a partir da leitura que os autores fazem da tradição marxista, entendendo-a como uma grande teoria sobre como se constroem os sujeitos históricos. Nas palavras dos autores:

[...] longe de um jogo racionalista, no qual os agentes sociais, perfeitamente constituídos em torno de interesses, travam uma luta definida por parâmetros transparentes, vimos as dificuldades da classe trabalhadora em constituir-se como um sujeito histórico, a dispersão e fragmentação de suas posicionalidades, a emergência de formas de reagregação social e política... (LACLAU e MOUFFE, 2015, p. 177-178, destaque meu)

A TPD, contrapondo-se a qualquer ponto de vista essencialista, nos quais os sujeitos históricos de determinado processo sejam pré-determinados ao processo histórico mesmo, desenvolve um entendimento do social cujo fundamento é a proliferação de identidades e formas de fazer política a partir do 
século XVIII. Dos anos 1700 em diante, uma revolução democrática difundiu o imaginário igualitário pelas sociedades europeias e possibilitou uma progressiva politização das relações sociais. Hierarquias foram assim redescritas como relações de opressão, colocando no horizonte a transformação destas relações como requisito para o progresso da liberdade. Esse imaginário, conjugado às experiências políticas de transformações e movimentações sucessivas, fez com que uma série de relações hierárquicas naturalizadas fossem consideradas opressivas e sua transformação se tornasse parte do horizonte dos agentes, incentivando ações no presente. A ideia de um espaço político único definido pela oposição público-privado implodiu com as lutas por igualdade e reconhecimento de grupos subalternizados. Pessoas pensando e agindo juntas para atingirem, na prática, a igualdade teorizada pluralizaram a esfera pública em um processo que se repete e transforma continuamente até o presente. A existência de esferas públicas ao invés de uma esfera pública única, que funciona para impedir certas relações significadas como injustas, é resultado do avanço do imaginário igualitário (idem, p. 269-270). Assim, resta claro que não se pode falar de esfera pública no singular e que ela possui uma relação umbilical com a dinâmica política ampla de uma sociedade.

Agora, como funciona a instauração de um público no ensino de História? Segundo Laclau e Mouffe (2015, p. 270), uma esfera pública se forma quando a lógica da equivalência subverte a lógica da diferença: indivíduos se percebem um grupo ao diagnosticarem estar vivendo no mesmo tempo sob condições similares. Isto é: quando estudantes são menos indivíduos do que uma nova geração de pessoas negras em um país que não combate o legado escravocrata, por exemplo. Isso significa que os saberes históricos escolares trazem consigo o potencial de criar uma esfera pública na medida em que os significantes e a organização da narrativa feita pelo professor coloca os alunos num continuum temporal em que eles/as partilham de um mesmo presente. Ou, melhor dizendo, na medida em que cria condições de possibilidade para a temporalização (TURIN, 2019, p. 11-12) dos estudantes.

A sincronização potencialmente realizada pelo ensino de História é antiga; de fato foi com esse objetivo que a disciplina foi inserida em currículos escolares. Apesar disto, não é comum se considerar, nestes termos, que a aula de História é uma esfera pública. O termo geralmente é utilizado para falar da imprensa, de discussões sobre a grande política. E, por causa destes contextos, 
ele acaba sendo restringido ao mundo da política partidária e ao teor negativo que vem com estes significantes. Esfera pública é o espaço onde se joga o jogo da política, onde se informam os cidadãos, onde se disputam mentes e corações.

Vejamos um trecho de aula de uma professora de História da rede pública estadual citada na introdução:

[...] e começaram [os Estados Unidos] a ver no presidente João Goulart um Fidel: “Imagina se o Brasil se torna comunista?". Não era nada disso. E aí, entreguismo: entregaram de bandeja nosso país. Ele [Goulart] era um nacionalista, nada a ver socialista. Tinha lá suas terras no sul, no Uruguai. Agora, ele tinha essa visão [da necessidade das reformas de base]. [...] Aí vai a classe média, faz suas manifestações "com Deus, pela família e pela liberdade". Não sei o que Deus tem a ver com isso, tratando socialismo como se fosse coisa do "demo" [...] O golpe falava em liberdade, mas o que foi implantado no Brasil nesses 21 anos foi uma das piores ditaduras. Onde estava a liberdade? Em lugar nenhum. (Aula de 17 out. 2014, terceiro ano, ditadura militar, adaptado)

Na mesma aula, algum tempo depois da exposição acima, a professora havia encaminhado seu fio explicativo para:

[...] É muito ruim, sabe, a gente perceber que as pessoas ainda não conseguiram ter o seu direito mais fundamental que é o da educação plenamente garantido. Não conseguiram. Porque eles veem as escolas públicas como um depósito de carentes, de pobres. Porque os filhos deles estão no tal São Bento, no Santo Inácio, no Sacre Coeur, no Notre Dame. No Corcovado, na Escola Parque. A mensalidade custa aí por baixo uns dois mil e pouco. E essa escola pública, que é a única que deveria ter - que tenham lá seu Sacre Coeur, quem quiser pagar dez mil que pague - mas essa escola aqui é nossa. Financiada com nossos impostos, com tudo que tem direito. (Aula de 17 out. 2014, terceiro ano, ditadura militar, adaptado)

Seguindo o fio das reformas de base, a professora chega ao presente dela e dos estudantes de $3^{\circ}$ ano de uma escola pública desvalorizada. A aula da qual o trecho acima foi tirado aconteceu poucos dias antes do segundo turno das eleições para a presidência daquele ano de 2014. Vê-se aqui uma operação historiográfica escolar stricto sensu que foi realizada quando o antagonismo radical entre dois campos, petistas e antipetistas, tornava-se a forma básica da 
política na grande esfera pública nacional. Essa informação é importante para compreender por que a professora, ao fazer uma exposição didática sobre as causas políticas do golpe de 1964 e falar do anticomunismo daquele período, julgou necessário organizar a narrativa de modo a chegar ao presente dos alunos - caracterizado pela iminência do momento democrático por excelência (as eleições) e pela assimetria de condições de fruição do direito à educação.

Uma estrutura discursiva é uma totalidade que "constitui e organiza as relações sociais" (LACLAU e MOUFFE, 2015, p. 167) criando uma interioridade e uma exterioridade que ajudam a construir sentidos por associação e por exclusão. A operação historiográfica escolar stricto sensu é parte de uma estrutura discursiva: a aula de História na escola é um espaço de criação de fronteiras - não absolutas - que ajudam a formar o sentido do que é dito dentro dela e do que é deixado de fora. O que se fala ali dentro é parte do conhecimento histórico legitimado pela ciência de referência, o ensino superior no qual a professora foi formada. ${ }^{12} \mathrm{O}$ que a professora exclui de maneira deliberada em sua prática, logo, não tem a mesma legitimidade ou não é importante.

Frente a esse auditório formado por alunas e alunos em idade de votar, o aspecto do conhecimento histórico que a professora destaca na exposição sobre 1964 de forma a negociar as distâncias entre ela e a turma, e entre a turma e o conhecimento histórico que ela quer que eles entendam, é a continuidade entre aquele período histórico e o presente: a permanência da ausência de reformas que efetivassem o direito à educação de qualidade. Aqui a aprendizagem histórica e público se conjugam. Após falar das razões e demandas pelo golpe militar, ela emenda um balanço da educação atual afirmando que o futuro pleiteado pelos grupos que defendiam as reformas de base em 1964 ainda hoje não foi alcançado, usando como exemplo a desigualdade entre escolas particulares com mensalidades caras e a escola pública da qual ela e seu auditório fazem parte. Importante lembrar que a estrutura física da escola em questão é limitada e a escola sofria uma série de pressões políticas da Secretaria de Educação (SILVA, 2019). A lógica da diferença, qual seja, aquela sala cheia de indivíduos, é subvertida e esses indivíduos são nomeados estudantes e sujeitos de um direito que não lhes é plenamente concretizado. O contraste do presente e do passado busca criar uma lacuna, um desconforto nos estudantes: por que a educação pública não é tão boa quanto a particular, se isso é demandado há tanto tempo? Se o golpe que derrubou as demandas por reformas implantou 
um regime ditatorial? Aqui ela espera que a experiência de aprendizagem se concretize numa resposta dos alunos: o conhecimento de que mais democracia é uma demanda antiga e ainda não cumprida para eles, estudantes de escola pública, embora funcione para quem pode pagar. Outra razão pela qual a professora faz esta comparação é para persuadir os alunos a compreenderem o que ela está ensinando: a desigualdade gritante entre os dois tipos de escola deve servir para provar que os problemas sociais existem e que a igualdade foi derrotada em 1964 e ainda não foi conquistada. A professora, ao apontar violações à igualdade, indica algo a ser feito, um horizonte do que deveria acontecer: o da igualdade. Esta é uma forma de provocar a ação sobre um futuro, indicando que tal agência é possível.

\section{REATIVAÇÃO DO POLÍTICO}

A teoria política do discurso ergue-se sobre uma concepção desenvolvida a partir de diversas fontes; tanto da teoria marxista quanto das incontornáveis contribuições de Foucault. O mais importante é entender que o conceito de discurso aqui não se restringe ao que é falado ou escrito, à língua no sentido restrito do termo; a noção de linguagem é ampliada para compreender qualquer prática articulatória. O título do último livro de Laclau, Os fundamentos retóricos da sociedade (tradução minha de The rhetorical foundations of society, 2014), ilustra isso. Para Laclau e Mouffe, o social se funda e se organiza por meio de práticas de significação, isto é, qualquer ato cometido por um ou mais seres humanos (LACLAU e MOUFFE, 2015b, p. 42). Um homem que bate em uma mulher com quem é casado pode ser considerado em seu direito enquanto patriarca ou como criminoso a ser denunciado. Outro exemplo ainda: um baixo salário pago a professoras com ampla formação em sua área, abaixo da média de outros profissionais com a mesma formação (OLIVEIRA, 2019), também produz significado para a sociedade, que considera a profissão desimportante. A ideia de discurso de Laclau e Mouffe engloba todos esses processos de significação através de um extenso aparelho conceitual, que não opõe fatos concretos e materiais a "discursos" (no sentido restrito), porque nada nos é apresentado no mundo fora de condições discursivas (LACLAU e MOUFFE, 2015b); em suma, essa teoria acaba por se tornar uma ontologia política do social, cuja significação tem raízes no político. 
Usei até aqui os termos política e político porque a diferença entre eles explica a dificuldade em definir esfera pública. Oliver Marchart (2007) entende essa diferenciação como um sintoma conceitual da percepção progressiva ao longo da segunda metade do século XX e no início do XXI, principalmente entre os pensadores que ele chama de "heideggerianos de esquerda", de que o mundo social não é baseado num fundamento inquestionável, mas que ainda assim deve ser baseado em algum fundamento - o que Butler (1998) sintetiza na expressão "fundamentos contingentes". A noção de fundamento é entendida aqui como aquilo que seria um ponto de irradiação de sentido para explicar uma totalidade, nesse caso, o social.

O político é esse momento instituinte da sociedade, um ato de poder quando um sentido é imposto e estabilizado, é aquilo que ordena o social numa sociedade que durará por um certo tempo. Reativar o político significa, assim, lembrar que certas práticas sedimentadas - como por exemplo a existência de escolas privadas com mensalidades altas, ou a dificuldade em efetivar plenamente o direito à educação - originam-se em contínuos atos de poder, seguindo daí que as coisas poderiam ter acontecido de outro modo. Essa dinâmica de esquecimento e lembrança, sedimentação e reativação do político, é o que explica porque algumas coisas que não eram consideradas políticas em outro momento podem ser politizadas em outro. $\mathrm{O}$ exemplo mais famoso talvez seja a palavra de ordem feminista "o pessoal é político". Vide também a militância pela autonomia alimentar que algumas vezes afirma que "comer é um ato político" para denunciar os monopólios de monoculturas que destroem o meio ambiente nacional: a alimentação é politizada para lançar luz sobre um tema pouco discutido, autonomia alimentar, para buscar transformar a abordagem governamental sobre a produção nacional de alimentos e políticas para o meio ambiente.

O político é o momento daquela contingência que sedimentou práticas ao longo do tempo, não porque era necessária, inerente àquela estrutura anterior, mas por uma articulação hegemônica estabelecida no contexto histórico. Falar do político é tocar na contingência de toda conjuntura e evento. Essa ucronia é parte de todo conhecimento histórico, como resumiu Raymond Aron: "Todo historiador, para explicar o que aconteceu, se pergunta sobre o que poderia ter acontecido" (apud RICOEUR, 2010, p. 303). No contexto da operação historiográfica escolar stricto sensu, a lembrança da contingência 
pode ser articulada a várias outras questões consideradas importantes para os alunos por parte dos professores, já que a explicação histórica escolar tem como parâmetro fundamental ser compreendida pelos estudantes. É assim que político e lembrança se associam. A disciplina História está constantemente lembrando das contingências responsáveis pelo presente. O trabalho historiográfico consiste em explicar por que uma ordem se estabeleceu de uma maneira e não de outra, seguindo os rastros de institucionalizações hegemônicas.

Por fim: por que falar em reativação do político e não simplesmente em ensino de História como esfera pública, por exemplo? É o potencial de reativação do político que explica as condições de possibilidade do ensino de história escolar de reabrir o futuro, ao criar esferas públicas. Dimensão política porque a natureza deste ensino envolve lidar com o lembrar e o esquecer, avaliar decisões e vitórias que não eram o único resultado possível nos seus contextos históricos. E porque um público, na definição de Laclau e Mouffe (2015), não implica necessariamente em uma abertura de futuros; não há teor normativo substantivo no acontecimento da formação de um grupo através do destaque daquilo que tais indivíduos hipotéticos têm em comum. Embora toda abertura de futuro e agência histórica passe pela criação de um público - e por isso o público pode ser compreendido como uma chave de temporalização -, nem todo público abre uma possibilidade de futuro e/ou busca a potência histórica de seus membros. Para que a criação de uma esfera pública aula de História torne esse ensino significativo, como as aulas da professora aqui citada foram consideradas, tem que haver uma reativação do político conjugada com a formação de uma esfera pública. Embora a aula analisada aqui realize essas duas ações, este certamente não é sempre o caso.

\section{CONSIDERAÇÕES FINAIS}

Embora os trabalhos do campo não costumem negar à sala de aula alguns aspectos hegemonicamente associados a uma esfera pública - lugar de efetivação de direitos, educação cidadã, espaço que deve ser gerido democraticamente, com acesso garantido para todas e todos, com direito de falar e de ouvir para todas e todos, entre outros -, usar este nome e nos apropriarmos do que colegas da ciência política e da teoria política pensaram sobre o assunto é esclarecedor. 
Seguindo a tradição do hibridismo das pesquisas no ensino de História, busquei inicialmente utilizar um entendimento de aprendizagem a partir de uma concepção aberta de sujeito, entendendo que os alunos não chegam e nem saem da escola acabados. Por isso, a relação com o saber os leva a caminhos que eles não poderiam imaginar, em que a aprendizagem é uma resposta (BIESTA, 2017) a uma pergunta que o ensino lhes coloca - fazer alguém compreender algo é persuadi-la (PENNA, 2013). Em seguida, apropriando-me do insight arendtiano de que uma esfera pública possui uma projeção ao futuro, mas deixando de lado as delimitações rígidas entre público e privado que a autora faz, incorporei um conceito de público que enriquece o ensino de História frente à temporalização neoliberal precária. Assim, o público no ensino de História é uma chave de temporalização, uma maneira de temporalizar os estudantes fora da angústia neoliberal de flexibilização forçada a cada presente que se passa. Os momentos durante os quais essa esfera pública se mantém colocam os estudantes no mesmo tempo e espaço, podendo pensar e planejar juntos. Estabelecida quando a lógica da equivalência (igualdade) se sobrepõe à lógica da diferença, essa esfera pública, quando combinada com a reativação do político, abre futuros. Por isso, a professora cujas aulas analisei aqui e em minha dissertação teve seu trabalho considerado significativo. Embora essa conclusão tenha surgido de um estudo de caso - e certamente mais pesquisas empíricas, especialmente as que acolham produções de estudantes, sejam necessárias para que o campo possa verificar ao longo do tempo a amplitude da aplicabilidade desta hipótese -, ela lida com problemas urgentes em nossa relação com o tempo.

Segundo Turin (2018), a História passa por um processo de desinstitucionalização frente a uma valorização crescente de orientações temporais outras, diferentes daquelas vigentes no século XIX e que favoreceram o estabelecimento da disciplina. As políticas neoliberais tentam hegemonizar o tempo acelerado, urgente, gerador de angústia (KEHL, 2009). Os termos do momento não são mais "formação", "desenvolvimento" ou mesmo "autonomia", mas sim "flexibilidade", "liberdade de escolha" e afins. O que se vê é um tempo sem um horizonte definido, sem um télos, e que destaca os movimentos de reação mais do que de ação (TURIN, 2018, p. 4). O futuro é algo para o qual se prepara, e não algo sobre o qual se age.

Como deve ser o ensino de História para as gerações que viverão o im- 
pacto do aquecimento global? No mês em que a revisão deste texto é feita, os incêndios no Pantanal, possivelmente causados por agropecuaristas, consumiram $26 \%$ de todo esse bioma (INCÊNDIOS, 2020). Um possível encaminhamento da conclusão sobre a dimensão política constitutiva do ensino de História é o campo avançar a discussão sobre como sermos professores de História, categoria tão engajada na produção de um futuro melhor, frente ao antropoceno.

\section{REFERENNCIAS}

ARAUJO, Valdei. O direito à história: o(a) historiador(a) como curador(a) de uma experiência histórica socialmente distribuída. In: Conversas sobre o Brasil: ensaios de crítica histórica. GUIMARÃES, BRUNO e PEREZ (Orgs.). Rio de Janeiro: Autografia, 2017.

ARENDT, Hannah. A condição humana. Trad. Roberto Raposo; revisão técnica e apresentação Adriano Correia. 12a ed. rev. Rio de Janeiro: Forense Universitária, 2015.

SILVA, Renata da Conceição Aquino da. Ensino de história como reativação do político. Dissertação (Mestrado em História Social). Faculdade de Formação de Professores, Universidade do Estado do Rio de Janeiro, São Gonçalo, 2019, 112 p.

BIESTA, Gert. Boa educação na era da mensuração. Cad. Pesqui., São Paulo, v. 42, n. 147, dez. 2012, p. 808-825.

BIESTA, Gert. The beautiful risk of education. Boulder, Co: Paradigm Publishers, 2013.

BIESTA, Gert. Para além da aprendizagem. Educação democrática para um futuro humano. São Paulo: Autêntica, 2017.

BOMFIM, Marcus. A (im)possibilidade da avaliação no ensino de história: uma análise a partir de exercícios de livros didáticos. Tese (Doutorado em Educação). Universidade Federal do Rio de Janeiro, Faculdade de Educação, Programa de Pós Graduação em Educação, 2019.

BROWN, Wendy. Cidadania sacrificial: neoliberalismo, capital humano e políticas de austeridade. Rio de Janeiro: Zazie Edições, 2019.

BUTLER, Judith. Fundamentos contingentes: o feminismo e a questão do "pós-modernismo. cadernos pagu, n. 11, p. 11-42, 1998.

CALDAS, Renan Rubim. A concepção de tempo histórico de alunos da educação básica: a produção e a avaliação de uma ferramenta de pesquisa. In: Anais do XVI Encontro Regional de História da Anpuh-Rio: Saberes e práticas científicas. XVI Encontro Regional de História da Anpuh-Rio: Saberes e práticas científicas: Rio de Janeiro, 2014, p. 1-9. 
CALDAS, Renan Rubim. O passado, o presente e o futuro na produção textual dos alunos da educação básica. In: Anais do $8^{\circ}$ Seminário Brasileiro de História da Historiografia - Variedades do discurso histórico: possibilidades para além do texto, 2014, Mariana - MG. $8^{\circ}$ Seminário Brasileiro de História da Historiografia - Variedades do discurso histórico: possibilidades para além do texto, 2014.

CERTEAU, Michel. A escrita da história. Rio de Janeiro: Forense Universitária, 2002.

CHEVALLARD, Yves. La transposición didáctica. Del saber sabio al saber enseñado. Buenos Aires: Aique Grupo Editor S.A., 1997.

CHAKRABARTY, Dipesh. O clima da História. Sopro, 91, jul. 2013.

CRUTZEN, Paul J.; STOERMER, Eugene F. The Anthropocene. IGBP newsletter, 41. Royal Swedish Academy of Sciences, Stockholm, Sweden, 2000.

DAVIS, Mike. "Living on the Ice Shelf: Humanity's Meltdown", 26 Jun. 2008. Disponível em: https://www.commondreams.org/views/2008/06/26/living-ice-shelf-humanitys-meltdown. Acesso em: 31 ago. 2020.

GABRIEL, Carmen Teresa. Relação com o saber: uma proposta de releitura pós-fundacional. In: LOPES, A.C.; OLIVEIRA, A.L.M. de; OLIVEIRA, G.G.S. de (Orgs). A teoria do discurso na pesquisa em educação. Recife: Editora UFPE, 2018, p. 217 250.

GUMBRECHT, Hans Ulrich. Depois de "depois de aprender com a história”: o que fazer com o passado agora?. In: Fernando Nicolazzi, Helena Miranda Mollo, Valdei Lopes de Araujo (Org.). Aprender com a história?: o passado e o futuro de uma questão. Rio de Janeiro: Editora FGV, 2011.

HARAWAY, Donna. Anthropocene, capitalocene, plantationocene, chthulucene: making kin. Environmental humanities, v. 6, n. 1, 2015, p. 159-165.

INCÊNDIOS no Pantanal continuam avançando e área destruída passa de 2,1 milhões de hectares em MT. Mato Grosso. G1 MT. 7 out. 2020. Disponível em: https://g1. globo.com/mt/mato-grosso/noticia/2020/10/07/incendios-no-pantanal-continuam-avancando-e-area-destruida-passa-de-21-milhoes-de-hectares-em-mt.ghtml. Acesso em: 13 out. 2020.

KEHL, Maria Rita. O tempo e o cão. São Paulo: Boitempo, 2009.

KOSELLECK, Reinhart. Futuro passado. Contribuição à semântica dos tempos históricos. Rio de Janeiro: Contraponto/Ed. PUC-Rio, 2006.

LACLAU, Ernesto e MOUFFE, Chantal. Hegemonia e estratégia socialista: por uma democracia radical. São Paulo: Intermeios, 2015 [1985].

LACLAU, Ernesto \& MOUFFE, Chantal. Pós-marxismo sem pedido de desculpas. In: Lopes, A. C. \& Mendonça, D. de (Orgs.) A teoria do discurso de Ernesto Laclau: ensaios críticos e entrevistas. São Paulo: Annablume, 2015b. 
LACLAU, Ernesto. New reflections on the revolution of our time. London/New York: Verso, 1990.

LACLAU, Ernesto. Hegemony and the Future of Democracy: Ernesto Laclau's Political Philosophy. Entrevista por Lynn Worsham e Gary A. Olson. In: OLSON, Gary A.; WORSHAM, Lynn (Ed.). Race, rhetoric, and the postcolonial. Albany (NY): SUNY Press, 1999.

LACLAU, Ernesto. Emancipação e diferença. Rio de Janeiro: EdUERJ, 2011.

LACLAU, Ernesto. A razão populista. São Paulo: Três Estrelas, 2013.

LACLAU, Ernesto. The rhetorical foundations of society. London/New York: Verso Books: 2014.

MARCHART, Oliver. Post-Foundational Political Thought: Political Difference in Nancy, Lefort, Badiou and Laclau. Edinburgh University Press, 2007.

MIGUEL, Luis Felipe. Da "doutrinação marxista" à "ideologia de gênero" - Escola Sem Partido e as leis da mordaça no parlamento brasileiro. Revista Direito e Práxis, vol. 7, no 15, 2016, p. 590-621.

MONTEIRO, Ana Maria. Professores de História: entre saberes e práticas. Rio de Janeiro: Mauad, 2007.

OLIVEIRA, Junia. Salário de professores com nível superior é 30\% menor que de profissionais com a mesma escolaridade. Educação. Estado de Minas. 1 jul. 2019. Disponível em: https://www.em.com.br/app/noticia/especiais/educacao/2019/07/01/ internas_educacao,1066019/professores-recebem-menos-que-outros-profissionais-de-nivel-superior.shtml. Acesso em: 31 ago. 2020.

PATEMAN, Carole. O Contrato Sexual. Rio de Janeiro: Paz e Terra, 1993.

PENNA, Fernando. Ensino de história: operação historiográfica escolar. Tese (Doutorado em Educação). PPGE-UFRJ. Rio de Janeiro, 2013.

PENNA, Fernando. Negociando a distância entre passado, presente e futuro em sala de aula: a relação entre o tempo histórico e a aprendizagem significativa no ensino de história. In: Anais do XVI Encontro regional de história da Anpuh-Rio: Saberes e práticas científicas. Rio de Janeiro: XVI Encontro regional de história da Anpuh-Rio: Saberes e práticas científicas, 2014, p. 1-9.

PENNA, Fernando. A total dúvida sobre o amanhã. História e Perspectivas, Uberlândia (53), p. 71-97, jan./jun. 2015.

PENNA, Fernando e SILVA, Renata. As operações que tornam a história pública: a responsabilidade pelo mundo e o ensino de história. In: MAUAD, Ana M; ALMEIDA, Juniele R.; SANTHIAGO, Ricardo. (Orgs.). História Pública no Brasil: Sentidos e itinerários. São Paulo, Letra e Voz, 2016.

PENNA, Fernando. "O ódio aos professores". In: AÇÃO EDUCATIVA (Org.) A ideo- 
logia do Movimento Escola Sem Partido - 20 autores desmontam o discurso. São Paulo: Ação Educativa, 2016.

RAMÔA, Hosana N. Produzindo presença em sala de aula: a oscilação entre a presença e o sentido na construção da aprendizagem. In: XVII Encontro de História da Anpuh-Rio: entre o local e o global, Rio de Janeiro, 2016.

RANGEL, Marcelo de Mello; ARAÚJO, Valdei Lopes de. Apresentação - Teoria e história da historiografia: do giro linguístico ao giro ético-político. História da Historiografia: International Journal of Theory and History of Historiography, v. 8, n. 17, 29 abr. 2015.

RICOEUR, Paul. Tempo e narrativa. 3 vol. São Paulo: Editora WMF Martins Fontes, 2010.

SALLES, Diogo e SILVA, Renata. O Escola sem Partido na desdemocratização brasileira. In: PENNA, F.; QUEIROZ, F.; FRIGOTTO, G. Educação democrática: antídoto ao Escola sem Partido. Rio de Janeiro: LPP UERJ, 2018.

SEFFNER, Fernando. Aprendizagens significativas em História: critérios de construção para atividades em sala de aula. In: Jogos e ensino de história. Porto Alegre: Editora da UFRGS, 2018, p. 35-46.

TURIN, Rodrigo. Entre o passado disciplinar e os passados práticos: figurações do historiador na crise das humanidades. TEMPO (NITERÓI), v. 24, p. 168-205, 2018.

TURIN, Rodrigo. Tempos precários: aceleração, historicidade e semântica neoliberal. 1. ed., vol. 1. Dansk: Zazie Edições, 2019.

\section{NOTAS}

${ }^{1}$ Este artigo é uma síntese e um desenvolvimento do terceiro capítulo da minha dissertação de mestrado, de mesmo título, defendida no PPGHS-UERJ/FFP em 2019. A orientação foi pelo Professor Dr. Fernando de Araujo Penna (PPGHS-UERJ/FEUFF). Foi desenvolvida com apoio de bolsa da CAPES.

${ }^{2}$ Agradeço aos avaliadores da revista, cujas sugestões e comentários muito enriqueceram a versão final deste texto.

${ }^{3}$ PEARL, Mike. "Climate despair" is making people give up on life. Environment. Vice. 11 jul. 2019. Disponível em: https://www.vice.com/en/article/j5w374/climate-despair-is-making-people-give-up-on-life. Acesso em: 13 out. 2020.

${ }^{4}$ Comecei a fazer parte do grupo de pesquisa algo em torno de um mês depois da aplicação dos questionários. 
${ }^{5}$ Para mais detalhes sobre como abordar teoricamente a política e o político foram primordiais, ver PENNA e SILVA, 2016.

${ }^{6}$ Ver, por exemplo, o texto de Valdei Araujo (2017) que sugere que nós historiadores sejamos curadores de histórias. Destaco que Araujo também elenca como preocupação nossa o atual estado de coisas da conjuntura política, lembrando que o lugar social a partir do qual produzimos é parte da democracia ora desmontada.

${ }^{7}$ Araujo e Rangel usam a expressão giro ético-político para nomear a crescente preocupação entre os historiadores de que os seus trabalhos tenham um impacto positivo sobre o mundo e participem dos debates na esfera pública nacional. Vê-se um sinal disso no crescimento da História Pública, por exemplo.

${ }^{8}$ No original: "In this sense a generalized rhetoric... transcends all regional boundaries and becomes coterminous with the structuration of social life itself."

${ }^{9}$ No original: "If part of the way in which the politics of learning is able to do its work stems from the suggestion that learning is a natural process and phenomenon, then the first step toward exposing the political work being done through learning is by denaturalizing learning, that is, highlighting what we might call the artificial nature of learning. One way to denaturalize the idea of learning is by acknowledging that 'learning' is an evaluative concept, not a descriptive one".

${ }^{10}$ Sobre avaliação no ensino de História, ver BOMFIM, 2019.

${ }^{11}$ Como exemplo, para uma síntese parcial de como definições de público e privado impactam demandas políticas que têm o gênero como categoria fundamental, ver SILVA, VENTURA e KRITSCH (2009).

${ }^{12}$ É por isto que movimentos de direita e extrema-direita tais como o Escola sem Partido e os fundamentalistas católicos e evangélicos que acumulam capital político em cima da "ideologia de gênero" ameaçam a estrutura escolar e, por consequência, o direito amplo à educação: eles corroem a pertinência epistemológica do conhecimento escolar. Na escola, a legitimidade científica do que é ensinado é representada pela formação e pelas remissões do professor ao saber acadêmico de referência (PENNA, 2013, p. 224). Como fica a legitimidade do professor quando a sociedade começa a acreditar que ele não trabalha de acordo com o saber de referência?

Artigo recebido em 31 de agosto de 2020. Aprovado em 06 de outubro de 2020. 